\title{
Propriedades físicas de solo em diferentes sistemas de preparo para o cultivo da batata-doce
}

\section{Soil physical properties under different soil managements for the cultivation of sweet potato}

\author{
Amarílis Beraldo Rós ${ }^{1}$; João Tavares Filho ${ }^{2 *}$; Graziela Moraes de Cesare Barbosa ${ }^{3}$
}

\section{Resumo}

Este trabalho teve por objetivo avaliar o impacto de sistemas de preparo em propriedades físicas de um Argissolo Vermelho Amarelo e no crescimento de raízes tuberosas de batata-doce. Para avaliação das propriedades físicas foi instalado experimento em blocos ao acaso, esquema de parcelas subdivididas. As parcelas corresponderam aos tratamentos preparo convencional com confecção de leiras e palha incorporada, preparo convencional com confecção de leiras sem palha, preparo reduzido com manutenção de palha na superfície e preparo reduzido sem manutenção de palha; e as subparcelas, a épocas de avaliação. Foram avaliadas densidade, porosidade total, macro e microporosidade, resistência à penetração de raízes e umidade gravimétrica do solo. Para avaliação do crescimento de raízes tuberosas foi instalado experimento no qual as parcelas corresponderam às formas de manejo do solo e as subparcelas, a épocas de colheita: 90, 120,150 e 180 DAP. Foram avaliadas as relações comprimento/diâmetro de raízes tuberosas. Concluiu-se que o preparo reduzido confere maior resistência à penetração, reduzindo o crescimento das raízes tuberosas em comprimento, e que a presença de palha incorporada no preparo convencional favorece manutenção de menor valor de densidade de solo e maior macroporosidade ao longo do tempo.

Palavras-chave: Ipomoea batatas, plantio direto, densidade do solo, resistência do solo à penetração, porosidade do solo, formato de raiz

\begin{abstract}
This study aimed to assess the impact of tillage systems on physical properties of an Alfissol type soil and on the growth of sweet potato tuberous roots. To assess the soil physical properties, an experiment was conducted in randomized blocks design, in split-plot scheme. The plots consisted of the treatments conventional tillage with making mounds and straw incorporated, conventional tillage with making mounds and without straw, reduced tillage with straw on the soil surface and reduced tillage without straw; and the subplots, to collect periods. The soil physical properties evaluated were soil bulk density, total soil porosity, soil macroporosity and soil microporosity, soil resistance to penetration and gravimetric soil water. For the assessment of the growth of sweet potato tuberous roots, it was adopted an experiment where the plots corresponded to the soil management forms and subplots to four collect periods: 90, 120, 150 and 180 (DAP). The length / roots diameter of individual roots relations were avaluated. It was concluded that the reduced tillage gives greater soil resistance to penetration of roots, by reducing the vertical growth of roots, and the presence of straw incorporated in the conventional tillage favors maintenance of lowest soil bulk density and highest soil macroporosity along the time.

Key words: Ipomoea batatas, no-tillage, soil bulk density, soil resistance to penetration, soil porosity, root shape
\end{abstract}

\footnotetext{
${ }^{1}$ Pesquisadora Científica III da Agência Paulista de Tecnologia dos Agronegócios, APTA, Polo Alta Sorocabana, Presidente Prudente, SP. E-mail: amarilis@apta.sp.gov.br

${ }^{2}$ Prof. Associado C, Dept ${ }^{\circ}$ de Agronomia, Universidade Estadual de Londrina, UEL, Londrina, PR. E-mail: tavares@uel.br

${ }^{3}$ Pesquisadora do Instituto Agronômico do Parará, IAPAR, Londrina, PR. E-mail: graziela_barbosa@iapar.br

* Autor para correspondência
} 


\section{Introdução}

No sistema de manejo convencional há intenso revolvimento da camada superficial, o que geralmente ocasiona compactação subsuperficial logo abaixo da camada mobilizada pelo arado, devido à carga aplicada pelo equipamento nessa camada (LLANILLO et al., 2006). Assim, o sistema favorece a degradação do solo pela perda da qualidade estrutural e aumento da erosão hídrica, especialmente quando não há adoção de práticas conservacionistas. Além disso, a adoção de tal sistema também promove a exposição dos compostos orgânicos e, conseqüentemente, sua degradação (DALAL et al., 2011), propiciando a deterioração física, química e biológica do solo (LEITE et al., 2003).

O plantio direto, ao contrário, promove mínima mobilização do solo que fica restrita à linha de semeadura/plantio e mantém resíduos vegetais na superfície do solo, constituindo-se, dessa forma, em alternativa de manejo capaz de preservar as propriedades físicas e a capacidade produtiva do solo (SILVA; MIELNICKZUK, 1997), reduzir as perdas por erosão hídrica e aumentar os estoques de matéria orgânica (LEITE et al., 2003).

A cultura da batata-doce é cultivada após intenso revolvimento do solo, promovido por meio do uso de arados e grades (ZERO; LIMA, 2005), embora Barrera (1986), na década de 1980, já recomendasse o plantio de batata-doce em sulcos nos solos arenosos, visto que a construção de leiras contribui para a perda da umidade do solo, podendo-se formar os camalhões durante as operações de capina e amontoa.

No Brasil, não há estudos sobre o cultivo de batata-doce sob preparo reduzido, mas outras culturas cujo órgão comercial é subterrâneo têm sido estudadas sob preparos conservacionistas do solo e os resultados são controversos. Em cultivo de mandioca, em Argissolo Vermelho textura arenosa, Silva et al. (2008) relataram diferenças entre os sistemas de plantio direto e convencional apenas na fase inicial do estabelecimento da cultura, onde o plantio convencional apresentou menor densidade, maior macroporosidade e porosidade total. De maneira semelhante, Tormena et al. (2002) comparando densidade, volume de macroporos e microporos, porosidade total e resistência do solo à penetração de raízes, em um Latossolo Vermelho distrófico, sob sistemas de preparo de solo convencional, mínimo e plantio direto, verificaram que o plantio direto proporcionou condições físicas menos favoráveis ao crescimento das plantas de mandioca, quando comparado aos outros dois sistemas. Contudo, Otsubo et al. (2008) concluíram ser viável a implantação da cultura em área minimamente preparada, em Argissolo Vermelho.

Fontes et al. (2007), no cultivo de batata, em solo de textura argilosa, relataram menor produtividade de tubérculos em sistema de plantio direto quando comparado ao uso de arado de aiveca associado à grade niveladora. No entanto, Carter e Sanderson (2001) consideraram o preparo reduzido do solo uma alternativa viável para a produção da cultura.

Assim, este trabalho teve por objetivo avaliar o impacto de sistemas de preparo sobre propriedades físicas de um Argissolo Vermelho Amarelo e sobre o crescimento de raízes tuberosas de batata-doce.

\section{Material e Métodos}

O trabalho foi conduzido na Agência Paulista de Tecnologias dos Agronegócios (APTA) - Polo Alto Sorocabana, em Presidente Prudente/SP, de abril a outubro de 2011. O solo foi classificado como Argissolo Vermelho Amarelo (EMBRAPA, 2006), com a seguinte composição granulométrica: $910 \mathrm{e}$ $930 \mathrm{~g} \mathrm{~kg}^{-1}$ de areia; 30 e $20 \mathrm{~g} \mathrm{~kg}^{-1}$ de silte; 60 e 50 $\mathrm{g} \mathrm{kg}^{-1}$ de argila, nas camadas $0-0,15$ e 0,15-0,30 m, respectivamente.

A área experimental vinha sendo ocupada por pastagem perene de Brachiaria decumbens há mais de 5 anos. A pastagem foi reformada por meio de preparo convencional do solo, com uso de grades de 
disco e niveladora. A pastagem originada a partir do banco de sementes foi dessecada por meio do uso de glifosato. Um mês após a dessecação, a palha foi roçada com o objetivo de facilitar seu manuseio.

Em abril de 2011, o experimento foi instalado. O delineamento experimental foi em blocos ao acaso, em esquema de parcelas subdivididas, com oito repetições. As parcelas foram constituídas pelos tratamentos preparo convencional com confecção de leiras e palha de $B$. decumbens incorporada (PCCP), preparo convencional com confecção de leiras sem palha incorporada (PCSP), preparo reduzido com manutenção de palha de $B$. decumbens na superfície (PRCP), preparo reduzido sem manutenção de palha superficial (PRSP). As subparcelas corresponderam a duas épocas de avaliação: 120 e 180 dias após plantio (DAP) de ramas de batata-doce. Para efeito de comparação entre solo de área cultivada e área com vegetação nativa, também foi avaliada área de mata nativa (MATA) sobre Argissolo Vermelho Amarelo, a aproximadamente $300 \mathrm{~m}$ do experimento, por meio do teste de comparação de médias de Dunnett a $5 \%$ de probabilidade de erro, visto que a área de mata não pode ser incluída na análise estatística como um tratamento por não atender aos pressupostos do respectivo delineamento experimental. $\mathrm{Na}$ área de mata nativa, os dados da análise granulométrica foram: 797 e $823 \mathrm{~g} \mathrm{~kg}^{-1}$ de areia; 138 e $122 \mathrm{~g} \mathrm{~kg}^{-1} \mathrm{de}$ silte; 65 e $55 \mathrm{~g} \mathrm{~kg}^{-1}$ de argila, nas camadas $0-0,15 \mathrm{e}$ 0,15-0,30 m, respectivamente.

O PCSP foi realizado por meio da utilização de aração com grade de disco, a uma profundidade de aproximadamente $0,25 \mathrm{~m}$, seguida de gradagem niveladora, e posterior levantamento de leiras (altura de aproximadamente $0,35 \mathrm{~m}$ ) com sulcador. O PCCP foi realizado da mesma forma, mas houve incorporação de palha (22 t ha- $\left.{ }^{-1}\right)$ ao solo durante a aração. No PRSP e no PRCP houve movimentação do solo apenas nas covas de plantio. No PRSP não havia palha na superfície do solo enquanto no PRCP a palha foi mantida $\left(22 \mathrm{t} \mathrm{ha}^{-1}\right)$.
Cada parcela experimental de $16,2 \mathrm{~m}^{2}$ apresentou três leiras/linhas distanciadas $0,9 \mathrm{~m}$ onde foram plantadas 20 ramas de batata-doce cultivar Uruguaiana de 0,3 m cada, oriundas de ponteiros de plantas, espaçadas a cada $0,3 \mathrm{~m}$, o que correspondeu a 37000 plantas ha ${ }^{-1}$. O plantio nas leiras do PCCP e PCSP foi realizado com abertura manual de orifício com $0,08 \mathrm{~m}$ de profundidade, colocação vertical da base da rama e enterrio também manual. Já no PRCP e PRSP foram abertas covas com $0,08 \mathrm{~m}$ de profundidade por aproximadamente $0,05 \mathrm{~m}$ de diâmetro com o auxílio de uma haste de bambu com ponta em formato de cone, com posterior colocação vertical da base da rama. A cobertura de porção da rama com solo foi realizada manualmente. Para a abertura das covas no PRCP, houve a remoção da palha apenas nos locais onde as covas seriam confeccionadas. A área útil foi constituída pela porção de solo que continha as 18 plantas centrais da leira/linha do meio.

As propriedades de solo avaliadas foram: densidade do solo (Ds), porosidade total (Pt), macroporosidade (Ma), microporosidade (Mi), resistência mecânica do solo à penetração $(\mathrm{RP})$ e umidade gravimétrica do solo (Ug).

Para a determinação de Ds, Pt, Ma e Mi foram coletadas amostras com estrutura indeformada, por meio de anéis volumétricos com capacidade para $100 \mathrm{~cm}^{3}$ de solo, em cada parcela e oito ao acaso na área da mata, aos 120 e 180 dias após plantio (DAP) de batata-doce, na porção mediana das camadas de $0-0,15 \mathrm{~m}$ e $0,15-0,30 \mathrm{~m}$. As coletas foram realizadas na leira/linha de plantio. A Ds foi determinada pelo método do anel volumétrico e a Pt por meio da relação existente entre a Ds e a densidade de partículas (valor médio de $2,63 \mathrm{~kg} \mathrm{dm}^{-3}$ ). A Mi foi obtida pelo método da mesa de tensão e a Ma pela diferença entre porosidade total e Mi. Os atributos físicos foram determinados de acordo com Claessen (1997).

A RP foi determinada por meio do uso de penetrômetro de impacto, aos 120 e 180 DAP. As 
medidas foram tomadas na leira/linha de plantio. Em cada parcela experimental foram obtidas três medidas de RP, das quais foram calculados valores médios. $\mathrm{Na}$ área de mata, a característica foi avaliada em 24 pontos inteiramente casualizados para obtenção de 8 médias para cada profundidade. Foi avaliado o número de impactos a cada $0,05 \mathrm{~m}$, na camada de $0-0,30 \mathrm{~m}$ de profundidade. Os dados obtidos em número de impactos por dm foram transformados para RP (MPa). Para esta transformação, utilizouse a equação apresentada por Stolf (1991). Os resultados foram apresentados em valores médios para cada $0,05 \mathrm{~m}$ de profundidade. Também foram retiradas amostras nas camadas $0-0,10 \mathrm{~m}, 0,10-0,20$ $\mathrm{m}$ e 0,20-0,30 m para determinação da Ug, obtida conforme descrito por Claessen (1997). Foram obtidos três valores por camada em cada parcela para obtenção de valores médios por camada.

As variáveis Ds, Pt, Ma e Mi foram submetidas à análise de variância e as médias foram comparadas pelo teste de Tukey. Os dados de RP foram avaliados e analisados utilizando um valor médio em cada profundidade. $O$ erro padrão da média foi utilizado para proceder à avaliação dos tratamentos em cada profundidade amostrada. Adotou-se 5\% de probabilidade de erro.

Também foi avaliado o formato das raízes tuberosas nos sistemas de preparo do solo, por meio da relação comprimento e diâmetro. Foram consideradas as raízes com massa fresca individual entre 80 e 1000 g. Essa parte do trabalho foi realizada em blocos ao acaso, com seis repetições, esquema de parcelas subdivididas, sendo as parcelas constituídas pelos quatro sistemas de preparo de solo descritos anteriormente e as subparcelas por quatro épocas de colheita: 90, 120, 150 e 180 DAP. As parcelas também foram constituídas por três leiras/linhas, sendo que a área útil foi composta pelas plantas centrais da leira/linha do meio.

Os dados obtidos com as relações comprimento/ diâmetro foram submetidos a análises de variância e as médias foram ajustadas a equações de regressão polinomial. O critério para a escolha do modelo foi a significância pelo teste $\mathrm{F}$ a $5 \%$ de probabilidade de erro e os maiores valores do coeficiente de determinação $\left(\mathrm{R}^{2}\right)$.

\section{Resultados e Discussão}

$\mathrm{Na}$ variável Ds não houve interação entre formas de preparo do solo e camadas, nas duas épocas avaliadas. Aos 120 DAP, a Ds nos preparos convencionais (PCCP e PCSP) foi menor que a obtida nos preparos de solo sem revolvimento (PRCP e PRSP) (Tabela 1). Esse resultado era esperado, pois o revolvimento de solo promovido por meio do uso de grade aradora e posterior confecção de leiras provoca intensa pulverização do solo, diminuindo a Ds na camada trabalhada. A Ds não foi influenciada pela presença ou ausência de palha dentro do mesmo preparo do solo, resultado semelhante ao encontrado por Boguzas, Kairyte e Jodaugiene (2010) em trabalho comparando diferentes sistemas de preparo do solo e presença e ausência de palha incorporada. Com relação às camadas, a porção mais superficial, 0-0,15 m, apresentou menor Ds que a camada mais profunda, provavelmente devido ao fato de a camada $0,15-0,30 \mathrm{~m}$ apresentar menor quantidade de matéria orgânica e ser menos influenciada pelo preparo do solo. 
Tabela 1. Densidade do solo aos 120 e 180 dias após plantio de batata-doce, em Argissolo Vermelho Amarelo submetido a preparo convencional com palha incorporada (PCCP), preparo convencional sem palha (PCSP), preparo reduzido com palha superficial (PRCP), preparo reduzido sem palha (PRSP) e área de mata nativa, em duas profundidades ${ }^{(1)}$.

\begin{tabular}{lcc}
\hline Preparo/utilização & $\begin{array}{c}120 \mathrm{DAP} \\
\left(\mathrm{kg} \mathrm{dm}^{-3}\right)\end{array}$ & $\begin{array}{c}180 \mathrm{DAP} \\
\left(\mathrm{kg} \mathrm{dm}^{-3}\right)\end{array}$ \\
\hline PCCP & $1,26 \mathrm{~A}^{*}$ & $1,38 \mathrm{~A}$ \\
PCSP & $1,29 \mathrm{~A}$ & $1,47 \mathrm{~B}^{*}$ \\
PRCP & $1,46 \mathrm{~B}^{*}$ & $1,50 \mathrm{~B}^{*}$ \\
PRSP & $1,50 \mathrm{~B}^{*}$ & $1,51 \mathrm{~B}^{*}$ \\
CV \% & 11,2 & 3,89 \\
MATA & 1,35 & 1,34 \\
\hline Profundidade & & \\
\hline $0-0,15 \mathrm{~m}$ & $1,31 \mathrm{a}$ & $1,40 \mathrm{a}$ \\
$0,15-0,30 \mathrm{~m}$ & $1,54 \mathrm{~b}$ & $1,53 \mathrm{~b}$ \\
CV\% & 11,2 & 3,89 \\
\hline
\end{tabular}

${ }^{(1)}$ Letras iguais entre os tipos de preparo do solo/utilização e entre profundidades não diferem entre si pelo teste de Tukey, a 5\% de probabilidade. Médias seguidas de * diferem significativamente da MATA pelo teste de Dunnett, a 5 \% de probabilidade.

Fonte: Elaboração dos autores.

Na segunda avaliação, 180 DAP, o PCCP apresentou Ds inferior ao PCSP, PRCP e PRSP, ou seja, nesta época é verificada a influência da presença de palha incorporada na manutenção de menor densidade do solo (Tabela 1). Tal fato devese à palha apresentar baixa densidade, elasticidade e susceptibilidade à deformação, o que a torna potencialmente capaz de atenuar as cargas aplicadas sobre o solo e, assim, auxiliar na manutenção da densidade do solo (BRAIDA; REICHERT; VEIGA, 2006). A Ds entre as camadas variou, sendo que a camada 0-0,15 m apresentou o menor valor. Essa diferença independe dos sistemas de preparo do solo, mas ocorreu devido a diferentes causas: no preparo convencional (PCCP e PCSP) foi devido à operação de confecção das leiras, no qual a camada superficial sofre menos compressão lateral do equipamento (sulcador) que as confecciona, enquanto em PRCP e PRSP, a diferença na densidade do solo pode ser explicada pelo fato de ter sido realizado o revolvimento do solo para renovação da pastagem, em fase anterior à instalação do experimento, principalmente na camada $0-0,20 \mathrm{~m}$.

Resultados referentes à densidade do solo são bastante variados. Carneiro et al. (2009) e Torres,
Fabian e Pereira (2011) observaram, em área de Latossolo Vermelho, que o sistema de preparo convencional do solo e o plantio direto não resultaram em diferença de densidade, assim como Assis e Lança (2005), em estudo em Nitossolo Vermelho, e Silva et al. (2006), em área de Argissolo Vermelho. No entanto, a comparação entre densidade de solo entre sistemas de preparo tem como resultado freqüente a menor densidade em camadas superficiais em solos convencionalmente preparados em relação a solos não revolvidos conforme verificado no presente estudo e em trabalhos de Secco et al. (2005) e Llanillo et al. (2006). Essa situação é devido à acomodação natural do solo em função da ausência de preparo no plantio direto e à diminuição da densidade promovida pelo revolvimento do solo no preparo convencional.

$\mathrm{Na}$ comparação entre MATA e preparos de solo, aos 120 DAP, PCCP e PCSP apresentaram Ds inferior e semelhante à área de vegetação nativa, respectivamente (Tabela 1). Os preparos reduzidos, PRCP e PRSP, apresentaram maior Ds que MATA, o que se deve, provavelmente, pela menor quantidade de matéria orgânica na camada superficial que MATA. Aos 180 DAP, apenas PCCP 
apresentou Ds semelhante à MATA, enquanto os demais tratamentos resultaram em maiores valores de Ds. Dessa forma, analisando-se as duas épocas de avaliação, os sistemas de preparo que proporcionaram valores de Ds mais próximos à Ds da MATA foram PCCP e PCSP.

A comparação entre os sistemas de preparo do solo e áreas não agrícolas (mata ou cerrado nativos) geralmente demonstra densidade de solo superior em solos utilizados para agricultura, sejam preparados convencionalmente ou em plantio direto, conforme relatado por Carneiro et al. (2009), Ferreira, Tavares Filho e Ferreira (2010) e Cunha et al. (2011), o que é justificado, segundo esses autores, pelo tráfego de máquinas e equipamentos agrícolas e pelo pisoteio de animais. Mas, assim como neste trabalho, Araújo, Goedert e Lacerda (2007) verificaram semelhança entre densidades de solo preparado convencionalmente e área de vegetação nativa.
Para os atributos Pt, Ma e Mi, aos 120 DAP não houve interação significativa entre formas de preparo do solo e camada analisada. Aos 180 DAP, houve interação entre os tratamentos apenas para Pt.

$\mathrm{Na}$ primeira avaliação, aos $120 \mathrm{DAP}$, a $\mathrm{Pt}$ e a Ma foram maiores em PC (PCCP e PCSP) que em PR (PRCP e PRSP), enquanto em Mi não houve diferença entre os tratamentos (Tabela 2). Aos 180 DAP, a Pt, na camada de $0-0,15 \mathrm{~m}$, foi superior em PCCP em relação aos demais preparos de solo (Tabela 3). Na camada $0,15-0,30 \mathrm{~m}$, não houve diferença entre os tratamentos. Quanto à Ma, PCCP apresentou valor superior a PRSP, sendo os demais preparos de solo semelhantes. Ma foi superior na camada mais superficial. A Mi foi semelhante entre os tratamentos.

Tabela 2. Porosidade total (Pt), macroporosidade (Ma) e microporosidade (Mi) aos 120 dias após plantio de batatadoce, em Argissolo Vermelho Amarelo submetido a preparo convencional com palha incorporada (PCCP), preparo convencional sem palha (PCSP), preparo reduzido com palha superficial (PRCP), preparo reduzido sem palha (PRSP) e área de mata nativa, em duas profundidades ${ }^{(1)}$.

\begin{tabular}{llcc}
\hline Preparo/utilização & Pt & $\begin{array}{c}\mathrm{Ma} \\
\left(\mathrm{cm}^{3} \mathrm{~cm}^{-3}\right)\end{array}$ & Mi \\
\hline PCCP & $0,52 \mathrm{~A}^{*}$ & $0,33 \mathrm{~A}$ & $0,20 \mathrm{~A}^{*}$ \\
PCSP & $0,51 \mathrm{~A}^{*}$ & $0,32 \mathrm{~A}$ & $0,19 \mathrm{~A}^{*}$ \\
PRCP & $0,45 \mathrm{~B}^{*}$ & $0,25 \mathrm{~B}^{*}$ & $0,20 \mathrm{~A}^{*}$ \\
PRSP & $0,43 \mathrm{~B}^{*}$ & $0,23 \mathrm{~B}^{*}$ & $0,20 \mathrm{~A}^{*}$ \\
CV\% & 4,22 & 15,2 & 14,21 \\
MATA & 0,48 & 0,33 & 0,16 \\
\hline Profundidade & & & $0,19 \mathrm{a}$ \\
\hline $0-0,15 \mathrm{~m}$ & $0,50 \mathrm{a}$ & $0,31 \mathrm{a}$ & $0,20 \mathrm{a}$ \\
$0,15-0,30 \mathrm{~m}$ & $0,45 \mathrm{~b}$ & $0,25 \mathrm{~b}$ & 14,21 \\
CV\% & 4,22 & 15,2 & \\
\hline
\end{tabular}

${ }^{(1)}$ Letras iguais entre os tipos de preparo do solo/utilização e entre profundidades não diferem entre si pelo teste de Tukey, a 5\% de probabilidade. Médias seguidas de * diferem significativamente da MATA pelo teste de Dunnett, a $5 \%$ de probabilidade.

Fonte: Elaboração dos autores. 
Tabela 3. Porosidade total (Pt), macroporosidade (Ma) e microporosidade (Mi) aos 180 dias após plantio de batatadoce, em Argissolo Vermelho Amarelo submetido a preparo convencional com palha incorporada (PCCP), preparo convencional sem palha (PCSP), preparo reduzido com palha superficial (PRCP), preparo reduzido sem palha (PRSP) e área de mata nativa, em duas profundidades.

\begin{tabular}{|c|c|c|c|}
\hline \multirow[b]{2}{*}{ Preparo/utilização } & Profundidade de $0-0,15 \mathrm{~m}$ & \multicolumn{2}{|c|}{ Profundidade de $0,15-0,30 \mathrm{~m}$} \\
\hline & \multicolumn{3}{|c|}{$\begin{array}{c}\mathrm{Pt}^{(1)} \\
\left(\mathrm{cm}^{3} \mathrm{~cm}^{-3}\right)\end{array}$} \\
\hline PCCP & $0,51 \mathrm{Aa}$ & \multicolumn{2}{|c|}{$0,43 \mathrm{Ab}$} \\
\hline PCSP & $0,46 \mathrm{Ba}^{*}$ & \multicolumn{2}{|c|}{$0,41 \mathrm{Ab}^{*}$} \\
\hline PRCP & $0,45 \mathrm{Ba}^{*}$ & \multicolumn{2}{|c|}{$0,41 \mathrm{Ab}^{*}$} \\
\hline PRSP & $0,43 \mathrm{Ba}^{*}$ & \multicolumn{2}{|c|}{$0,41 \mathrm{Aa}^{*}$} \\
\hline $\mathrm{CV} \%$ & 4,99 & \multicolumn{2}{|c|}{4,99} \\
\hline MATA & 0,52 & \multicolumn{2}{|c|}{0,45} \\
\hline Preparo/utilização & \multicolumn{3}{|c|}{$\mathrm{Ma}\left(\mathrm{cm}^{3} \mathrm{~cm}^{-3}\right)^{(2)}$} \\
\hline PCCP & $0,25 \mathrm{~A}$ & \multicolumn{2}{|c|}{ Profundidade } \\
\hline PCSP & $0,22 \mathrm{AB}^{*}$ & \multirow{2}{*}{$0-0,15 \mathrm{~m}$} & \multirow{2}{*}{$0,24 \mathrm{a}$} \\
\hline PRCP & $0,22 \mathrm{AB}^{*}$ & & \\
\hline PRSP & $0,20 \mathrm{~B}^{*}$ & \multirow{2}{*}{$0,15-0,30 \mathrm{~m}$} & \multirow{2}{*}{$0,20 \mathrm{~b}$} \\
\hline $\mathrm{CV} \%$ & 14,38 & & \\
\hline MATA & 0,30 & $\mathrm{CV} \%$ & 6,38 \\
\hline Preparo/utilização & \multicolumn{3}{|c|}{$\operatorname{Mi}\left(\mathrm{cm}^{3} \mathrm{~cm}^{-3}\right)^{(2)}$} \\
\hline PCCP & $0,22 \mathrm{~A}$ & \multicolumn{2}{|c|}{ Profundidade } \\
\hline PCSP & $0,22 \mathrm{~A}$ & \multirow{2}{*}{$0-0,15 \mathrm{~m}$} & \multirow{2}{*}{$0,22 \mathrm{a}$} \\
\hline PRCP & $0,21 \mathrm{~A}$ & & \\
\hline PRSP & $0,22 \mathrm{~A}$ & \multirow{2}{*}{$0,15-0,30 \mathrm{~m}$} & \multirow{2}{*}{$0,21 \mathrm{a}$} \\
\hline $\mathrm{CV} \%$ & 11,77 & & \\
\hline MATA & 0,18 & $\mathrm{CV} \%$ & 6,86 \\
\hline
\end{tabular}

${ }^{(1)}$ Letras maiúsculas iguais entre os tipos de preparo do solo/utilização na coluna e na mesma profundidade e letras minúsculas iguais entre as duas profundidades e no mesmo preparo do solo/utilização não diferem entre si pelo teste de Tukey, a 5\% de probabilidade. ${ }^{(2)}$ Letras iguais entre os tipos de preparo do solo/utilização e entre profundidades não diferem entre si pelo teste de Tukey, a 5\% de probabilidade. Médias seguidas de * diferem significativamente da MATA pelo teste de Dunnett, a $5 \%$ de probabilidade.

Fonte: Elaboração dos autores.

Da mesma forma que a densidade do solo, os atributos relacionados à porosidade do solo respondem de maneira diferenciada, conforme o tipo de solo, sua utilização e seu histórico de cultivo. Silva et al. (2006), semelhantemente ao presente trabalho, também verificaram maior quantidade de macroporos em camada superficial de Argissolo Vermelho preparado convencionalmente em relação ao plantio direto, o que, segundo Cruz, Goedert e Sousa (2003), deve-se à desestruturação do solo sob preparo convencional. Contudo, alguns trabalhos demonstram semelhanças entre preparo convencional e plantio direto nos atributos porosidade total (SILVA et al., 2006) e macro e microporosidades (ASSIS; LANÇA, 2005).
A avaliação dessas características nas duas épocas de avaliação indica que a palha incorporada auxiliou na manutenção de maior Pt ao longo do tempo, visto que o PCCP e PCSP foram semelhantes aos 120 DAP e, aos 180 DAP, PCCP apresentou maior Pt que PCSP, assim como ocorreu com Ds. A semelhança entre PCSP, PRCP e PRSC, aos 180 DAP, deve-se à acomodação natural do solo em função do tempo em áreas cultivadas. Em trabalho de Silva et al. (2008) ocorreu algo semelhante: na camada 0-0,10 m de um Argissolo Vermelho textura arenosa, na primeira avaliação, o preparo convencional do solo resultou em maiores valores de porosidade total e macroporosidade e semelhante valor de microporosidade em relação ao plantio 
direto, enquanto na segunda avaliação, 15 meses após, o solo não apresentou diferenças nesses atributos nos dois sistemas.

Na comparação com MATA, aos 120 DAP, PC (PCCP e PCSP) resultou em maior Pt e PR (PRCP e PRSP), em menor. Ma em MATA foi superior aos valores obtidos em PRCP e PRSP, enquanto Mi nos solos preparados foi superior à área de MATA (Tabela 2). Aos 180 DAP, apenas PCCP apresentou Pt semelhante à MATA, enquanto os demais tratamentos apresentaram Pt inferior, resultado que também ocorreu com Ma. Mi também não diferiu entre os tratamentos (Tabela 3). Esses resultados diferem dos obtidos por Cunha et al. (2011), os quais verificaram maiores valores de $\mathrm{Pt}$ e $\mathrm{Ma}$ em solo sob vegetação nativa.
Com relação à RP, aos 120 DAP, PCCP e PCSP apresentaram-se semelhantes em todas as profundidades avaliadas (Figura 1). Em PC (PCCP e PCSP) não houve resistência à penetração de raízes até $0,15 \mathrm{~m}$, enquanto $\mathrm{PRCP}$ e PRSP apresentaram RP desde a camada 0-0,05 m, mesmo estes tratamentos apresentando maior umidade gravimétrica que PC. Na camada 0,15-0,25 m, PC continuou apresentando menor RP que PR. Apenas na profundidade de $0,30 \mathrm{~m}$, os tratamentos tornaramse semelhantes. Em trabalho de Tormena et al. (2002), o preparo convencional também apresentou menor RP que plantio direto na camada $0-0,25 \mathrm{~m}$. MATA apresentou comportamento intermediário, apresentando semelhanças ao PR na camada 0-0,05 $\mathrm{m}$ e ao PC, na camada $0,25-0,30 \mathrm{~m}$.

Figura 1. Resistência do solo à penetração e umidade gravimétrica aos 120 DAP em Argissolo Vermelho Amarelo submetido a preparo convencional com palha incorporada (PCCP), preparo convencional sem palha (PCSP), preparo reduzido com palha superficial (PRCP) e preparo reduzido sem palha (PRSP).
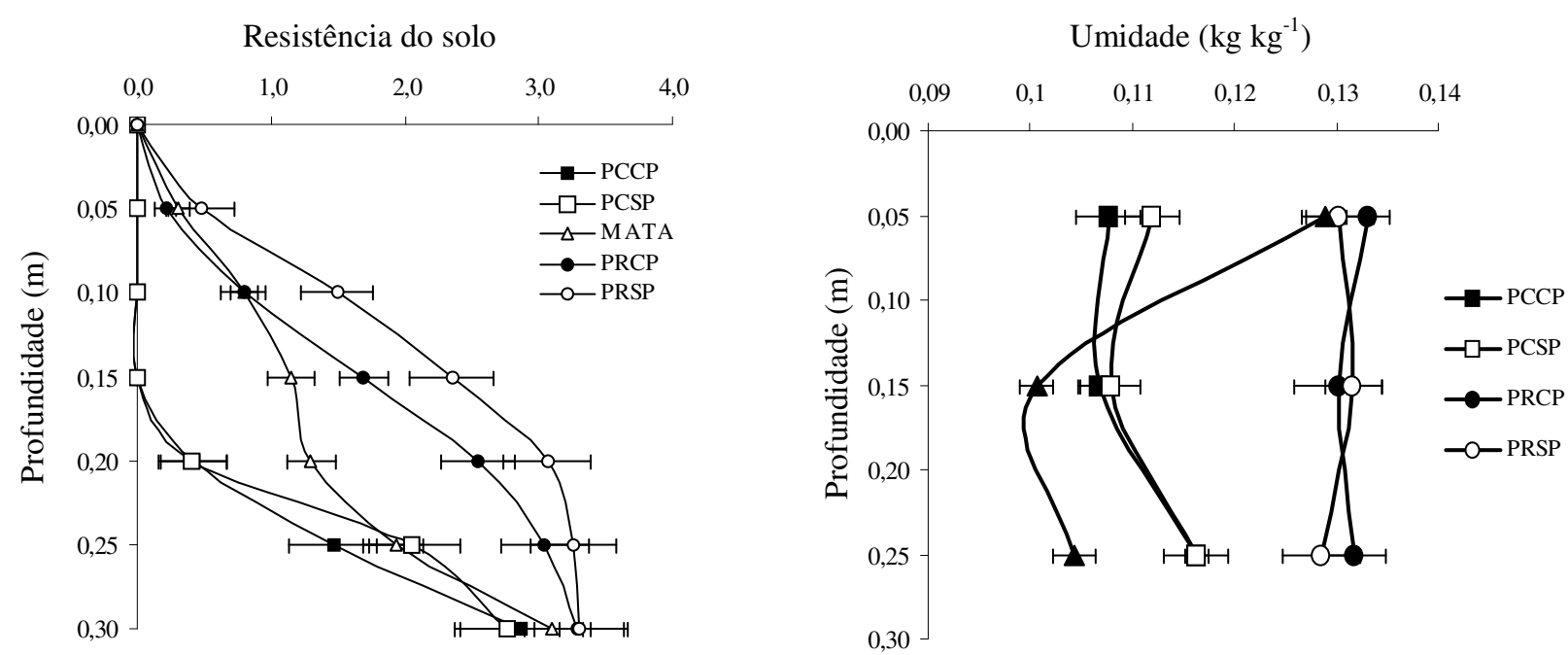

Fonte: Elaboração dos autores.

A umidade presente no solo apresentou valores maiores no PR em relação ao PC, mas tal fato não foi suficiente para tornar a RP semelhante entre os sistemas (Figura 1). A maior RP no PR em relação ao PC e também à MATA está relacionada à maior Ds e menores Pt e Ma encontrados nesta época de avaliação. Contudo, diferentes valores de Ds entre tratamentos não resultam obrigatoriamente em diferentes valores de resistência à penetração de raízes, visto que outros fatores também interferem (umidade e textura do solo), como verificado entre PCSP e MATA, aos 120 DAP (iguais Ds, mas 
diferentes RP), e em trabalho de Prado, Roque e Souza (2002), os quais verificaram que não houve correlação entre as duas propriedades em um Latossolo Vermelho submetido a diferentes sistemas de preparo do solo.

Aos 180 DAP, o solo apresentava maior teor de umidade que aos $120 \mathrm{DAP}$, o que justifica a menor RP ocorrida em todos os tratamentos na segunda época de avaliação. A RP de PR manteve-se superior à RP de $\mathrm{PC}$ (Figura 2). $\mathrm{PC}$ apresentou RP semelhante à MATA na camada $0-0,25 \mathrm{~m}$, pois houve maior acomodação do solo revolvido e, conseqüentemente ampliação do valor de Ds. No entanto, áreas com vegetação natural, geralmente, apresentam menores valores de resistência à penetração que solos com uso agrícola, conforme observado em trabalho de Tavares Filho, Barbosa e Ribon (2010).

Figura 2. Resistência do solo à penetração e umidade gravimétrica aos 180 DAP em Argissolo Vermelho Amarelo submetido a preparo convencional com palha incorporada (PCCP), preparo convencional sem palha (PCSP), preparo reduzido com palha superficial (PRCP) e preparo reduzido sem palha (PRSP).

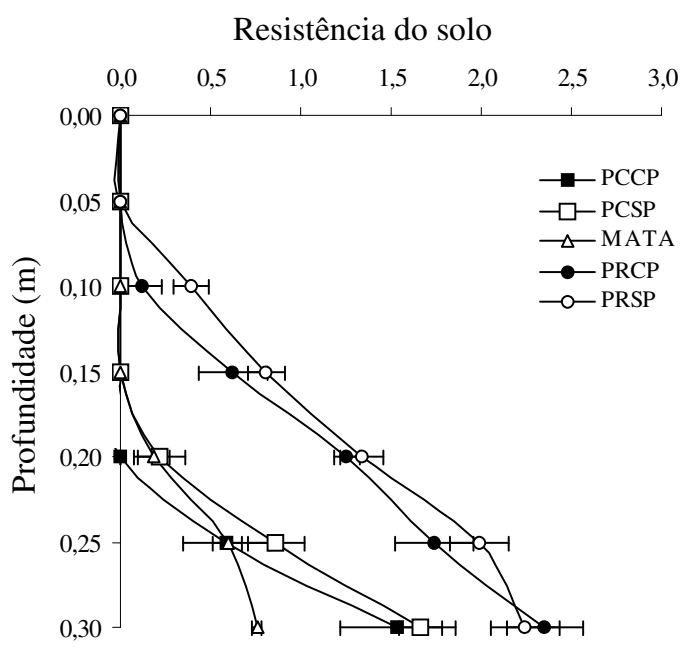

Fonte: Elaboração dos autores.

A presença de palha superficial no PRCP não promoveu maior manutenção de água no solo que PRSP, diferentemente do observado por Fasinmirin e Reichert (2011) que enfatizam que a presença de palha na superfície do solo favorece a manutenção da umidade do solo, devido a, segundo Martorano et al. (2009), temperatura máxima no solo e amplitude térmica menores, e, consequentemente, menor perda de água por evaporação (AGBEDE, 2010). No presente trabalho, o fator responsável pelo maior teor de umidade no solo foi o sistema de preparo do solo, no qual os preparos reduzidos com e sem palha superficial destacaram-se.

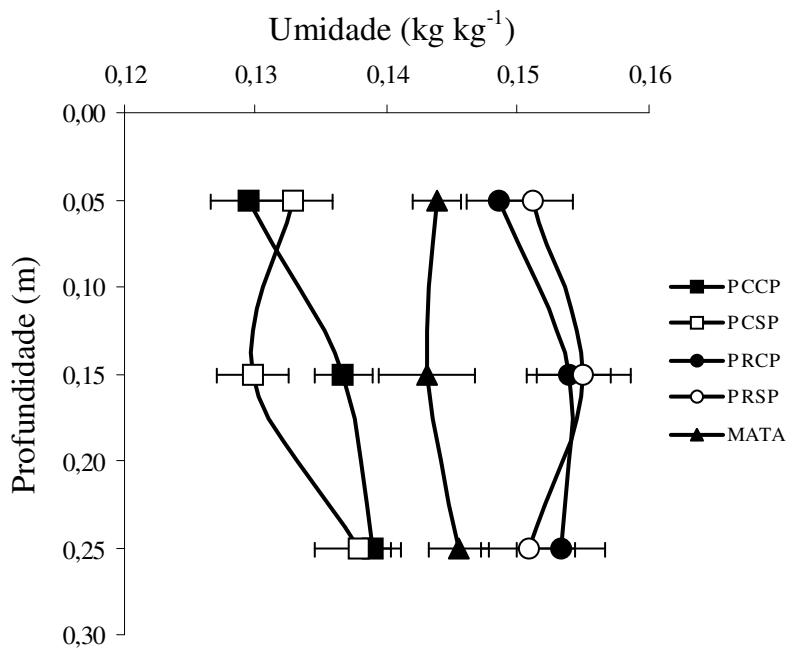

O sistema de preparo do solo também influenciou o formato das raízes tuberosas. Não houve interação significativa entre sistemas de preparo e épocas de colheita. PCCP e PCSP proporcionaram maiores valores nas relações entre comprimento e diâmetro de raízes tuberosas que PRCP e PRSP (Figura 3A). Dessa maneira, o formato das raízes tuberosas no PR (PRCP e PRSP) foi menos alongado que no PC (PCCP e PCSP). Tal fato deve-se à maior resistência à penetração das raízes encontrada no PR, propriedade que, segundo Barley, Farrell e Greacen (1965), afeta diretamente o alongamento das raízes. 
Figura 3. Relação entre comprimento e diâmetro de raízes tuberosas em Argissolo Vermelho Amarelo submetido a preparo convencional com palha incorporada (PCCP), preparo convencional sem palha (PCSP), preparo reduzido com palha superficial (PRCP) e preparo reduzido sem palha (PRSP) (A), em diferentes épocas de avaliação (B).

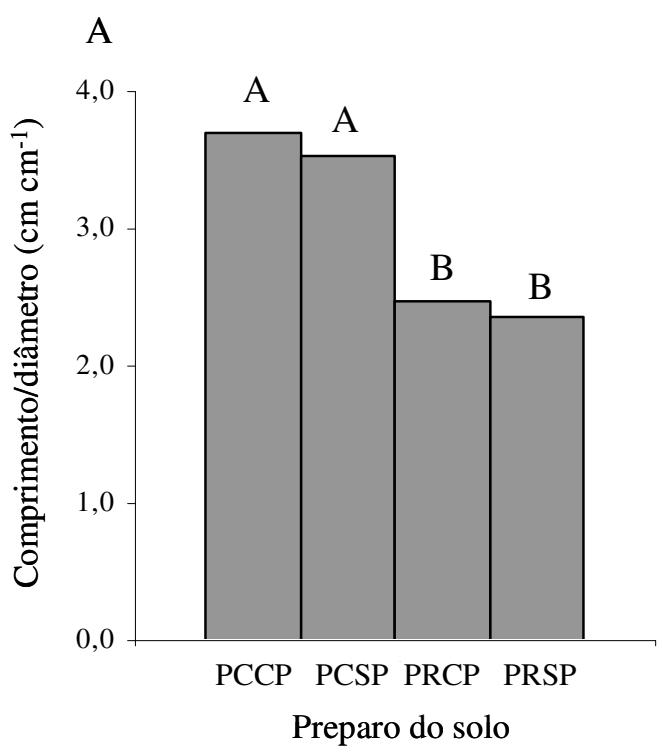

Fonte: Elaboração dos autores.

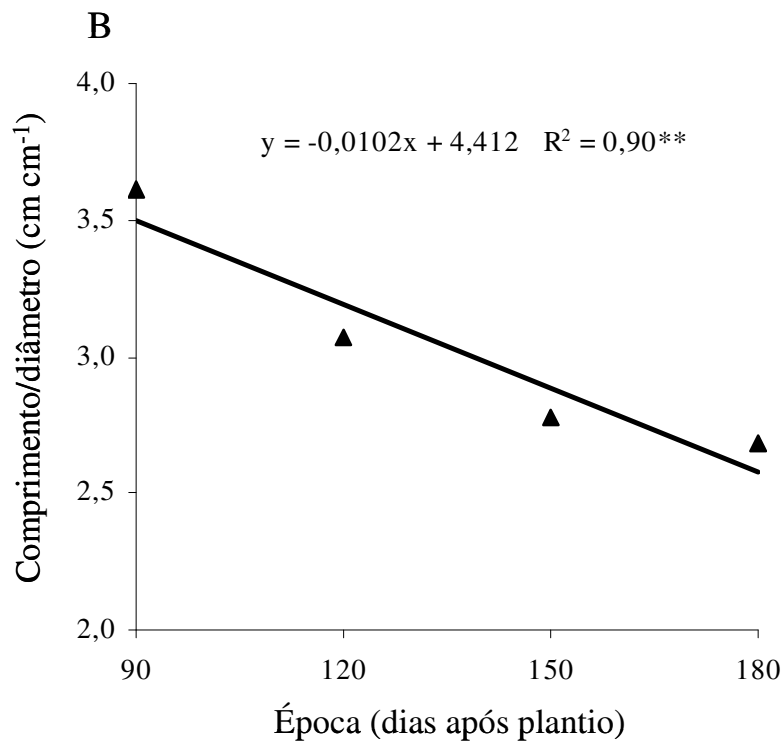

A relação entre comprimento e diâmetro apresentou resposta estimada linear decrescente em função do tempo (Figura 3B). Assim, o diâmetro das raízes tuberosas foi constantemente ampliado em relação ao comprimento das raízes em função da maior permanência das plantas no campo.

\section{Conclusões}

1. A presença de palha incorporada no preparo convencional favorece a manutenção de menor valor de densidade de solo e maior macroporosidade ao longo do tempo.

2. O preparo reduzido confere maior resistência à penetração de raízes no solo que o preparo convencional, mas favorece a manutenção de água no solo.

3. O preparo convencional com palha incorporada é o sistema de preparo do solo que apresenta propriedades físicas mais semelhantes à área de mata.
4. As diferenças nos atributos físicos do solo decorrentes dos diferentes sistemas de preparo do solo promovem alterações no formato de raízes tuberosas de batata-doce.

\section{Referências}

AGBEDE, T. M. Tillage and fertilizer effects on some soil properties, leaf nutrient concentrations, growth and sweet potato yield on an Alfisol in southwestern Nigeria. Soil \& Tillage Research, Amsterdam, v. 101, n. 1, p. $25-$ $35,2010$.

ARAÚJO, R.; GOEDERT, W. J.; LACERDA, M. P. C. Qualidade de um solo sob diferentes usos e sob Cerrado nativo. Revista Brasileira de Ciência do Solo, Viçosa, v. 31, n. 5, p. 1099-1108, 2007.

ASSIS, R. L. de; LANÇAS, K. P. Avaliação dos atributos físicos de um Nitossolo Vermelho distroférrico sob sistema plantio direto, preparo convencional e mata nativa. Revista Brasileira de Ciência do Solo, Viçosa, v. 29, n. 4, p. 515-522, 2005. 
BARLEY, K. P; FARRELL, D. A.; GREACEN, E. L. The influence of soil strength on the penetration of a loam by plant roots. Australian Journal of Soil Research, Collingwood, v. 3, n. 1, p. 69-79, 1965.

BARRERA, P. Batata-doce: uma das doze mais importantes culturas do mundo. São Paulo: Ícone, 1986. $91 \mathrm{p}$.

BOGUZAS, V.; KAIRYTE, A.; JODAUGIENE, D. Soil physical properties and earthworms as affected by soil tillage systems, straw and green manure management. Zemdirbyste Agriculture, Akademija, v. 97, n. 3, p. 3-14, 2010.

BRAIDA, J. A.; REICHERT, J. M.; VEIGA, M. da. Resíduos vegetais na superfície e carbono orgânico do solo e suas relações com a densidade máxima obtida no ensaio proctor. Revista Brasileira de Ciência do Solo, Viçosa, v. 30, n. 4, p. 605-614, 2006.

CARNEIRO, M. A. C.; SOUZA, E. D. de; REIS, E. F. dos; PEREIRA, H. S.; AZEVEDO, W. R. dos. Atributos físicos, químicos e biológicos de solo de cerrado sob diferentes sistemas de uso e manejo. Revista Brasileira de Ciência do Solo, Viçosa, v. 33, n. 1, p. 147-157, 2009.

CARTER, M. R.; SANDERSON, J. B. Influence of conservation tillage and rotation length on potato productivity, tuber disease and soil quality parameters on a fine sandy loam in eastern Canada. Soil \& Tillage Research, Amsterdam, v. 63, n. 1-2, p. 1-13, 2001.

ClAESSEN, M. E. C. (Org.). Manual de métodos de análise de solo. 2. ed. Rio de Janeiro: EMBRAPA, 1997. $212 \mathrm{p}$.

CRUZ, A. C. R.; GOEDERT, W. J.; SOUSA, D. M. G. de. Atributos físicos e carbono orgânico de um Argissolo Vermelho sob sistemas de manejo. Pesquisa Agropecuária Brasileira, Brasília, v. 27, n. 6, p. 11051112, 2003.

CUNHA, E. Q.; STONE, L. F.; MOREIRA, J. A. A.; FERREIRA, E. P. de B.; DIDONET, A. D.; LEANDRO, W. M. Sistemas de preparo do solo e culturas de cobertura na produção orgânica de feijão e milho. I - Atributos físicos do solo. Revista Brasileira de Ciência do Solo, Viçosa, v. 35, n. 2, p. 589-602, 2011.

DALAL, R. C.; ALLEN, D. E.; WANG, W. J.; REEVES, S.; GIBSON, I. Organic carbon and total nitrogen stocks in a Vertisol following 40 years of no-tillage, crop residue retention and nitrogen fertilization. Soil \& Tillage Research, Amsterdam, v. 112, n. 2, p. 133-139, 2011.
EMPRESA BRASILEIRA DE PESQUISA AGROPECUÁRIA - EMBRAPA. Sistema brasileiro de classificação de solos. Brasília: EMBRAPA, 2006. 306 p.

FASINMIRIN, J. T.; REICHERT, J. M. Conservation tillage for cassava (Manihot esculenta $\mathrm{Crantz}$ ) production in the tropics. Soil \& Tillage Research, Amsterdam, v. 113, n. 1, p. 1-10, 2011.

FERREIRA, R. R. M.; TAVARES FILHO, J.; FERREIRA, V. M. Efeitos de sistemas de manejo de pastagens nas propriedades físicas do solo. Semina: Ciências Agrárias, Londrina, v. 31, n. 4, p. 913-932, 2010.

FONTES, P. C. R.; NUNES, J. C. S.; FERNANDES, H. C.; ARAÚJO, E. F. Características físicas do solo e produtividade da batata dependendo de sistemas de preparo do solo. Horticultura Brasileira, Brasília, v. 25, n. 3, p. 355-359, 2007.

LEITE, L. F. C.; MENDONÇA, E. S.; MACHADO, P. L. O. A.; MATOS, E. S. Total C and N storage and organic $\mathrm{C}$ pools of a red-yellow podzolic under conventional and no tillage at the Atlantic Forest Zone, Southeastern Brazil. Australian Journal Soil Research, Amsterdam, v. 41, n. 4, p. 717-730, 2003.

LLANILLO, R. F.; RICHART, A.; TAVARES FILHO, J.; GUIMARÃES, M. de F.; FERREIRA, R. R. M. Evolução de propriedades físicas do solo em função dos sistemas de manejo em culturas anuais. Semina: Ciências Agrárias, Londrina, v. 27, n. 2, p. 205-220, 2006.

MARTORANO, L. G.; BERGAMASCHI, H.; DALMAGO, G. A.; FARIA, R. T. de; MIELNICZUK, J.; COMIRAN, F. Indicadores da condição hídrica do solo com soja em plantio direto e preparo convencional. Revista Brasileira de Engenharia Agrícola e Ambiental, Campina Grande, v. 13, n. 4, p. 397-405, 2009.

OTSUBO, A. A.; MERCANTE, F. M.; SILVA, R. F. da; BORGES, C. D. Sistemas de preparo do solo, plantas de cobertura e produtividade da cultura da mandioca. Pesquisa Agropecuária Brasileira, Brasília, v. 43, n. 3, p. 327-332, 2008.

PRADO, R. de M.; ROQUE, C. G.; SOUZA, Z. M. de. Sistemas de preparo e resistência à penetração e densidade de um Latossolo Vermelho eutrófico em cultivo intensivo e pousio. Pesquisa Agropecuária Brasileira, Brasília, v. 37, n. 12, p. 1795-1801, 2002.

SECCO, D.; ROS, C. O. da; SECCO, J. K.; FIORIN, J. E. Atributos físicos e produtividade de culturas em um Latossolo Vermelho argiloso sob diferentes sistemas de manejo. Revista Brasileira de Ciência do Solo, Viçosa, v. 29, n. 3, p. 407-414, 2005. 
SILVA, I. F. da, MIELNICKZUK, J. Avaliação do estado de agregação do solo afetado pelo uso agrícola. Revista Brasileira de Ciência do Solo, Viçosa, v. 21, n. 2, p. 313319, 1997.

SILVA, M. A. S.; MAFRA, A. L.; ALBUQUERQUE, J. A.; ROSA, J. D.; BAYER, C.; MIELNICZUK, J. Propriedades físicas e teor de carbono orgânico de um Argissolo Vermelho sob distintos sistemas de uso e manejo. Revista Brasileira de Ciência do Solo, Viçosa, v. 30, n. 2, p. 329-337, 2006.

SILVA, R. F.; BORGES, C. D.; GARIB, D. M.; MERCANTE, F. M. Atributos físicos e teor de matéria orgânica na camada superficial de um Argissolo Vermelho cultivado com mandioca sob diferentes manejos. Revista Brasileira de Ciência do Solo, Viçosa, v. 32, n. 6, p. 2435-2441, 2008.

STOLF, R. Teoria e teste experimental de fórmulas de transformação dos dados de penetrômetro de impacto em resistência do solo. Revista Brasileira de Ciência do Solo, Viçosa, v. 15, n. 3, p. 229-235, 1991.
TAVARES FILHO, J.; BARBOSA, G. M. de C.; RIBON, A. A. Physical properties of dystrophic Red Latosol (Oxisol) under different agricultural uses. Revista Brasileira de Ciência do Solo, Viçosa, v. 34, n. 3, p. 925 933, 2010.

TORMENA, C. A.; BARBOSA, M. C.; COSTA, A. C. S. da; GONÇALVEZ, A. C. A. Densidade, porosidade e resistência à penetração em Latossolo cultivado sob diferentes sistemas de preparo do solo. Scientia Agricola, Piracicaba, v. 59, n. 4, p. 795-801, 2002.

TORRES, J. L. R.; FABIAN, A. J.; PEREIRA, M. G. Alterações dos atributos físicos de um Latossolo Vermelho submetido a diferentes sistemas de manejo. Ciência e Agrotecnologia, Lavras, v. 35, n. 3, p. 437-445, 2011.

ZERO, V. M.; LIMA, S. L. Manejo e produtividade da cultura da batata - doce (Ipomoea batatas) no município de Presidente Prudente - SP. Energia na Agricultura, Botucatu, v. 20, n. 4, p. 94-117, 2005. 